\title{
UTERINE DECIDUALIZATION IN RATS GIVEN TESTOSTERONE PROPIONATE NEONATALLY
}

\author{
M. A. KRAMEN* AND D. G. JOHNSON \\ Departments of Obstetrics and Gynecology and Physiology, \\ University of Kansas Medical School, Kansas City, Kansas, U.S.A.
}

(Received 26th Fune 1974)

There has been little success in inducing a decidual reaction in the uteri of adult female rats given androgen neonatally. Burin, Thevenot-Duluc \& Mayer (1963) reported a positive reaction after scratching the antimesometrial lining and giving progesterone $(5 \mathrm{mg}$ ) daily for 8 days, but the incidence of success, the age of the animals, and the criteria for decidualization were not given. Barraclough (1967) reported that $25 \%$ of adult females given HCG to induce ovulation, and reserpine to sustain pseudopregnancy, produced a positive decidual reaction. All other reports are negative. The reasons for failure are not clear. Lack of oestrogen-binding capacity has been documented (McGuire \& Lisk, 1969) and may play an important rôle; the availability of progesterone receptors in the uteri of such females is unknown.

In the present study, attempts were made to induce a decidual cell reaction in the uteri of adult females of various ages given different doses of testosterone propionate (TP) at 5 days of age. Holtzman strain female rats were given $50 \mu \mathrm{g}$, $250 \mu \mathrm{g}$ or $1250 \mu \mathrm{g}$ TP on the 5 th day after parturition. A decidual reaction was induced in adult females by scratching the entire antimesometrial length of one uterine horn; the contralateral horn served as the control. A $300 \%$ increase in weight of the former over the latter was considered significant (DeFeo, 1963). Progesterone was administered subcutaneously dissolved in $0.1 \mathrm{ml}$ sesame oil, as was oestradiol benzoate (OB) when it was used. Animals were killed on the 10 th day after treatment began.

Young adults were given progesterone for 9 days and were killed on the 10th day (Table 1). Uterine trauma on Day 6 elicited a response in all rats (Groups $2 \mathrm{~A}$ and $3 \mathrm{~A}$ ). The need for progesterone was indicated by the lack of response with oil or with early withdrawal of treatment. The $2 \mathrm{mg}$ dose of progesterone was used in all further tests. The progesterone apparently caused a reduction in gonadotrophin from the pituitary because ovarian weight was reduced (Groups $2 \mathrm{~A}$ and $3 \mathrm{~A}$ versus $4 \mathrm{~A}$ and $5 \mathrm{~A}$ ).

A positive response was obtained in about $25 \%$ of 3- to 4-month-old females given $1250 \mu \mathrm{g}$ TP neonatally (Table 1). Again, oestrogen did not increase the incidence of positive responses. The steroid treatment reduced the ovarian weight of the rats in three of the four groups. These results are similar to those

\footnotetext{
* Present address : Departments of Obstetrics and Gynecology and Anatomy, The University of Texas Health Science Center at San Antonio, San Antonio, Texas 78284, U.S.A.
} 


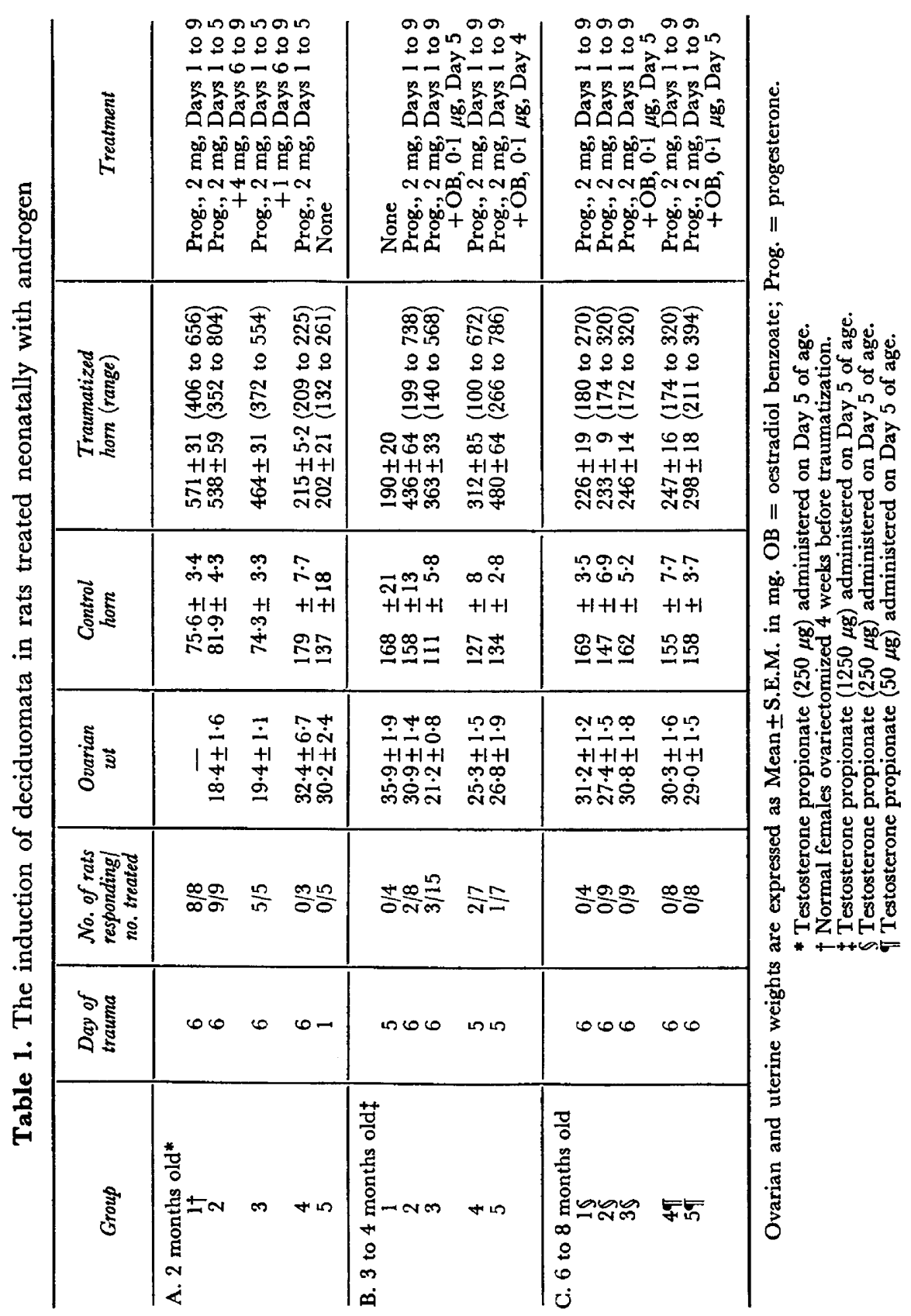


obtained by Barraclough (1967) who used animals treated neonatally with $1000 \mu \mathrm{g} \mathrm{TP}$.

Rats 6 to 8 months old failed to give a positive response when given progesterone, even when $0 \cdot 1 \mu \mathrm{g} \mathrm{OB}$ was added on the day before traumatization (Table 1). Females treated with $50 \mu \mathrm{g} \mathrm{TP}$ on Day 5 also failed to produce a decidual reaction when they were of this age.

No decidualization techniques have been conclusively proved to have physiological significance, but they do permit identification of the endocrine conditions which prepare the uterus for blastocyst implantation and also give an indication of uterine sensitivity to hormonal stimuli (DeFeo, 1967). The general lack of success in obtaining a response in females treated with TP is probably related to the dose used, and to the age of the animals. When young, the females treated with $250 \mu \mathrm{g}$ TP gave responses equal to those of normal females. Kramen (1974) has demonstrated successful implantation in young animals given $50 \mu \mathrm{g} \mathrm{TP}$. The total failures seen in all females 6 to 8 months old, however, indicate that the uterine capacity to form a decidual reaction is lost quite early in these animals. With the high dose of TP, most uteri were incapable of the response at 3 to 4 months of age.

The reasons for the failure to elicit a decidual response are not clear, but uterine histology provides some clues. Before 3 months of age, the uterine epithelium of females treated with TP shows simple, tall columnar cells with basal nuclei and some vacuolization. Stromal glands with low columnar to cuboidal epithelium are sparsely distributed among the dense, fibrous and reticular stroma. The vaginal epithelium in these animals shows stratified squamous proliferation characteristic of constant vaginal oestrus. As the animals age, the uterine lining takes on the appearance of the vaginal epithelium showing metaplasia from columnar to stratified squamous; the latter appears at about 3 months and is essentially complete by 5 months of age. Hyperplasia and/or metaplasia of the uterine epithelium has been noted in rodents treated with androgens (Takewaki, 1965). In some cases, the transformation will occur even in the absence of the ovaries. The possibility of a direct effect of androgen upon the uterine response to subsequent hormonal stimulation cannot be overlooked.

Changing endocrine levels in ageing females treated with androgens may also be involved in the failure to elicit a decidual reaction. The endocrine environment is presumed to be stable. The only hormonal changes that could be correlated with an effective dose of TP and age of the animals are serum prolactin concentrations. These increase with age and with the dose of TP given on Day 5 (Mallampati \& Johnson, 1973). The rôle of prolactin in uterine physiology is unclear, and must await further investigation.

\section{REFERENCES}

BARRaclough, C. A. (1967) Modification in reproductive function after exposure to hormones during the prenatal and early postnatal period. In Neuroendocrinology, vol. II, Chap. 19, pp. 61-99. Eds. L. Martini and W. F. Ganong. Academic Press, New York.

Burin, P., Thevenot-Duluc, A. J. \& Mayer, G. (1963) Exploration des potentialités de l'hypophyse et des effecteurs des hormones genitales chez les Rattes en oestrus permanent provoqué par une injection postnatale de testostérone. C. r. hebd. Séanc. Acad. Sci., Paris, 157, 1258-1260. 
DeFro, V. J. (1963) Temporal aspect of uterine sensitivity in the pseudo-pregnant or pregnant rat. Endocrinology, 72, 305-316.

DeFeo, V. J. (1967) Dedicualization. In Cellular Biology of the Uterus, Chap. 8, pp. 192-290. Ed. R. M. Wynn. Appleton-Century-Crofts, New York.

KRAMEN, M. A. (1974) Implantation in rats treated neonatally with testosterone propionate. F. Reprod. Fert. 38, 461-463.

MCGurRE, J. L. \& LISK, R. D. (1969) Oestrogen receptors in the androgen or oestrogen sterilized female. Nature, Lond. 221, 1068-1069.

Mallampati, R. S. \& Johnson, D. C. (1973) Serum and pituitary luteinizing hormone, folliclestimulating hormone, and prolactin levels in gonadectomized male, female, and androgenized female rats treated with oestradiol benzoate. F. Endocr. 59, 209-216.

TAKEWAKI, K. (1965) Hormone-independent persistent changes in reproductive organs in female rats induced by early postnatal treatment with androgen. Proc. Japan Acad. 41, 310-315. 